\title{
АНАТОЛИЙ ГРИГОРЬЕВИЧ ВИШНЕВСКИЙ И ЕГО ДЕМОГРАФИЧЕСКАЯ СИСТЕМА
}

\author{
ВЛАДИМИР ШКОЛЬНИКОВ
}

\begin{abstract}
В статье делается обзор научных достижений и творческого наследия выдающегося российского демографа А.Г. Вишневского (1934-2021). Труды Вишневского стали классическими и связали в рамках единой демографической теории огромное количество разнообразных и, казалось бы, разрозненных фактов демографической истории и современности. Приводятся иентральные положения демографической системы Вишневского, которая последовательно развивалась на протяжении полувека, но приняла законченную форму лишь к середине 2010-х годов. Подчеркивается то новое, что внес А.Г. Вишневский в теорию демографического перехода, и его решаюшая роль 6 институализачии российской демографической науки. Статья опирается как на труды А.Г. Вишневского, так и на личный опыт многолетнего творческого сотрудничества с их автором.
\end{abstract}

Ключевые слова: демографическая система Вишневского, демографический переход, демографический рост, автономность демографических прочессов.

До сих пор очень трудно осознать уход из жизни Анатолия Григорьевича Вишневского. Трагическое событие - результат действия зловещего вируса. Воспринимается больше как несчастный случай, а не как неотвратимый итог неизлечимой болезни. Казалось, что все еще можно исправить, привлечь медицинских авторитетов и проч... Но нет. Срыв в последний момент, когда казалось, что все пошло на поправку.

Кажется странным и несправедливым, что грубое и примитивное вмешательство вируса остановило работу тонкого, мощного, проницательного и изощренного интеллекта с огромным запасом знаний в самых разных областях, наделенного к тому же художественным воображением.

Мне выпала удача работать под руководством Анатолия Григорьевича с конца 1988 г. до отъезда в Институт демографических исследований общества Макса Планка (Германия) в апреле 2000 г. Анатолий Григорьевич во многом определил мою профессиональную судьбу. В 1987 г. он был оппонентом моей кандидатской диссертации. Затем пригласил к себе в Отдел демографии Института проблем народонаселения АН СССР, дал возможность войти в настоящую академическую науку, а затем инициировал мое участие в многолетнем российско-французском проекте. В последние годы, после образования в ВШЭ Международной лаборатории населения и здоровья, в которой я работаю научным руководителем, нам вновь удавалось общаться.

\footnotetext{
ВЛАДИМИР МИХАЙЛОВИч ШКОЛЬНИКОВ (shkolnikov@demogr.mpg.de), ИНСТИТУТ ДЕМОГРАФИЧЕСКИХ ИССЛЕДОВАНИЙ ОБЩЕСТВА МАКСА ПЛАНКА, ГЕРМАНИЯ. НАЦИОНАЛЬНЫЙ ИССЛЕДОВАТЕЛЬСКИЙ УНИВЕРСИТЕТ «ВЫСШАЯ ШКОЛА ЭКОНОМИКИ», РОССИЯ.
}

СТАТЬЯ ПОСТУПИЛА В РЕДАКЦИЮ В МАРТЕ 2021 Г. 


\section{Личность}

Он был настоящий интеллигент и человек Мира. Деликатный и вдумчивый. От него исходила аура спокойствия и уверенности. Он обладал колоссальной работоспособностью и умением мотивировать других. Говорил всегда негромко, но так, что в любой аудитории сразу устанавливалась тишина не столько из-за его высокого авторитета, сколько из-за того, что все боялись пропустить что-то интересное.

Он всегда умел понять и выделить главное на данный момент, предложить оптимальный выход из самых сложных и неожиданных ситуаций.

А.Г. Вишневский ничего не принимал на веру. Все подвергал спокойному анализу. Он был позитивным человеком, с которым было приятно общаться. При этом мы с ним нередко спорили. Он всегда очень твердо стоял на своем.

Bce, о чем я сейчас скажу, лишь в слабой степени основывается на информации, полученной от самого Анатолия Григорьевича. Он довольно мало говорил о себе и о том, как он создавал свою науку, работая в одиночестве. Я знал только о том, что мы делали вмести и что он делал с другими сотрудниками. Остальное я взял из его книг и/или додумал сам.

\section{РАБОТА КАЖДЫЙ ДЕНЬ}

В течение многих десятилетий А.Г. Вишневский контролировал все текущие и организационные дела своих научных коллективов, сначала в отделах демографии разных академических институтов, наиболее длительно в Центре демографии и экологии человека ИНП РАН (в 1993-2006 гг.), а потом в Институте демографии ВШЭ (в 2007-2021 гг.). Неутомимо и энергично занимался работой над журнальными статьями, руководил аспирантами, вел научно-просветительскую, публицистическую деятельность (газеты, телевидение, радио...), читал лекции студентам и магистрантам, редактировал научнопопулярный «Демоскоп Weekly», а затем и научное «Демографическое обозрение», выпускал под своей редакцией каждый год коллективный сборник - демографический доклад «Население России», организовывал издание ряда коллективных монографий, участвовал в официальных мероприятиях, искал финансирование на науку, ездил во множество командировок и многое-многое другое.

Самое загадочное и непостижимое - все это все-таки не было самым главным в научной и интеллектуальной жизни Анатолия Григорьевича. Главным были его научные и художественные книги. Когда он ухитрялся их писать с учетом колоссальной загруженности? Загадка. Возможно, рано утром и поздно вечером. Возможно, ночью. По выходным. Кроме того, он был очень эффективен в планировании своего времени.

Анатолий Григорьевич Вишневский принадлежал к чрезвычайно редкому и неуклонно уходящему от нас типу настоящих гуру, теоретиков, мыслителей и моральных авторитетов. 


\section{ВКЛАД В НАУКУ}

Конечно, главный вклад - это все его книги по демографии от «Демографической революции» 1976 г. (Вишневский 1976) до «Демографической истории и демографической теории» 2019 г. (Вишневский 2019). Они составили основной идейный и теоретический корпус современной российской демографии. Эти книги и принципиальные научные статьи А.Г. Вишневского стали классикой социальной науки. Хотя его книги строго научные, но благодаря своему образному языку они были и остаются вдохновляющим чтением.

А.Г. Вишневскому вместе с А.Г. Волковым, Е.М. Андреевым, Л.Е. Дарским и их коллегами по Отделу демографии НИИ ЦСУ СССР принадлежит основная заслуга возрождения российской демографии в 1970-1980-е годы. Эта группа профессионалов высочайшего класса вернула нашу демографию к мировому уровню, которого достигали в 20-е годы ХХ века С.А. Новосельский, В.В. Паевский, М.В. Птуха и Ю.А. КорчакЧепурковский.

В момент прихода А.Г. Вишневского в демографию в СССР господствовала «советская комплексная наука о народонаселении», находившаяся под влиянием идеологических установок, склонная к экономическому детерминизму, к вере в эффективность целенаправленного макровоздействия на демографические процессы и к тому же к замалчиванию реальных проблем, таких как повышение смертности, архаичность внутрисемейного регулирования рождаемости и других, ставших абсолютно очевидными уже в 1960-1970-х годах. Вопреки фактам, отрицалась конвергенция демографических процессов между СССР и другими странами мира. Нельзя сказать, что А.Г. Вишневский с этим как-то специально «боролся». Но ему эта борьба удалась вполне, благодаря тому, что он просто гнул свою линию объективности, доказательности, опоры на факты, исторический опыт, достижения мировой демографической науки и применение современных методов математики и статистики. И в конце концов именно это направление А.Г. Вишневского стало преобладающим в российской демографии, а он сам был по праву признан профессиональным сообществом в качестве главного российского демографа.

Во многом благодаря международному авторитету Анатолия Григорьевича и его особым связям с французской демографической наукой, одной из ведущей в мире, российские демографы и их работы получили возможность через сотрудничество и совместные проекты влиться в мировую демографию и занять там заметное место.

Книги А.Г. Вишневского, его лекции и публичные выступления оказали влияние на формирование множества его более молодых коллег, мотивировали многих на занятия наукой.

А.Г. Вишневский оказывал влияние на интеллектуальную жизнь всей страны. Особенно значимой была в этом отношении его книга «Серп и рубль» (Вишневский 1998; 2010), дающая ключ к пониманию движущих сил российской истории и российского общества. Она с успехом была принята и за рубежом, чему способствовал ее перевод на французский. 


\section{НАУЧНЫЙ МЕТОД И НАУЧНЫЕ ПРЕДПОЧТЕНИЯ}

А.Г. Вишневский выстроил свою демографию как целостную систему, в которой все логично и взаимосвязано. Это очень классическая конструкция. При ее построении он был строго избирателен, использовал исключительно надежные, доказательные и интуитивно прозрачные факты, методические инструменты, обнажающие причинно-следственные связи, и отказывался от некоторых менее надежных, хотя (иногда) и модных, и цитируемых подходов. Например, он прохладно относился к большому научному направлению, основанному на микроданных опросов о предпочтениях и намерениях, к микросимуляционным моделям и вообще микроуровневым исследованиям, делающим выводы на основе статистических ассоциаций.

Мне кажется, что ему были не очень интересны многочисленные, полезные, но не создающие больших смыслов, научные статьи, в которых, например, показывалось, что шведские врачи имеют более высокую рождаемость, чем представители других видов умственного труда. А.Г. Вишневский сам был автором и соавтором многочисленных эмпирических исследований, например в анализе пространственных закономерностей смертности или рождаемости, но всегда искал в полученных результатах не столько интересные факты, сколько проявление фундаментальных механизмов, приводящих в движение демографические процессы.

А.Г. Вишневский был сосредоточен на больших задачах, не умножал сущности без надобности, извлекая максимум из обобщенной теории демографического перехода и вовлекая в ее орбиту все больше и больше эмпирических фактов и статистических связей.

Анатолий Григорьевич никогда не занимался так называемой agent-based demography. Это - направление в демографии, основанное на анализе демографической реальности с точки зрения агента (живущего в этой реальности отдельного индивида). В российской демографии пример такого подхода - книга Б.Ц. Урланиса «История одного поколения» (Урланис 1968). Примечательно, что А.Г. Вишневский написал на эту тему не академическую монографию, а роман «Жизнеописание Петра Степановича К» (Вишневский 2013), который даже вошел в short list номинантов на литературную премию «Русский Букер».

\section{ДЕМОГРАФИЧЕСКАЯ СИСТЕМА ВИШНЕВСКОГО}

Как известно, теория демографической революции (или демографического перехода) началась работами Адольфа Ландри и Уоррена Томсона, Александра Кулишера и ряда других коллег (см. (Вишневский, Тольц 2015)), которые еще до Второй мировой войны сформулировали представления об исторически сменяющих друг друга режимах воспроизводства населения. Во второй половине 1940-х годов она была развита сотрудниками Принстонского университета, прежде всего Фрэнком Ноутстейном, которые сосредоточили свое внимание на переходе в области рождаемости, более глубоко исследованном позже в рамках так называемого «Принстонского проекта» под руководством Энсли Коула. Эта теория позволила понять внутренние механизмы наблюдавшегося в то время географического разнообразия режимов рождаемости и 
семейной структуры (Coale, Watkins 1986).

В 1970-е годы теория демографического перехода была усилена в отношении долговременной эволюции смертности (эпидемиологический переход А. Омрана ((Omran 1971)) и в отношении режима воспроизводства населения в целом (Chenais 1986). В орбиту перехода была также включена и последняя составляющая движения населения - миграция (Zelensky 1971; Coleman 2006).

В СССР до 1970-х годов теория демографического перехода оставалась почти не известной, была объектом поверхностной критики как еще одна «ошибочная буржуазная теория». В 1973 г. вышла в свет знаменитая статья Вишневского «Демографическая революция» (Вишневский 1973), а в 1976 г. - еще более знаменитая книга под тем же названием, которая была переиздана в 2005 г. (Вишневский 1976). Она оказала огромное влияние на российскую демографию и социальные науки. А.Г. Вишневский приводит в ней многочисленные новые и красноречивые факты и новые логические связи, превращающие уже известные представления о смене режимов воспроизводства в по-настоящему связную теорию. Главное - линия исторических типов воспроизводства населения, выработанная с применением системного подхода к анализу огромного разнообразия частных наблюдений. Сильное воздействие этой книги на умы определялось не только ее основным содержанием, но и живостью изложения, и логичным и прозрачным для понимания стилем, который сделал ее понятной неспециалистам. В 1982 г. выходит еще одна важная книга Вишневского «Воспроизводство населения и общество», в которой более развитая система понятий и методов была применена к изучению глобальных историко-демографических процессов (Вишневский 1982), а также годом позднее - получившая широкий резонанс коллективная монография, посвященная демографической динамике в СССР и России (Вишневский, Волков 1983). Позднее его теоретические взгляды на историю населения России будут развиты в фундаментальной коллективной монографии под редакцией А.Г. Вишневского «Демографическая модернизация России, 1900-2000» (Вишневский 2006).

А.Г. Вишневский продолжал последовательно развивать теорию демографического перехода как изменения демографической системы. В его работах 2000-2010-х годов в теорию были добавлены новые важные положения и получили дальнейшее развитие элементы, которые были лишь намечены в работах 1970-1980-х годов. Наиболее полное и всестороннее изложение теории демографического перехода, как ее видел Анатолий Григорьевич, можно найти в его последней книге (курсе лекций) «Демографическая история и демографическая теория», опубликованной ВШЭ в 2019 г. на основе обязательного курса лекций, который он читал в рамках магистерской программы «Демография» (Вишневский 2019).

Большинство понимает демографический переход как переход от режима высокой рождаемости и высокой смертности к режиму низкой рождаемости и низкой смертности, вызванный модернизацией традиционных аграрных обществ и их превращением в современные индустриальные. Такой подход преобладал не только в работах принстонских демографов, но был очевиден и в первых книгах А.Г. Вишневского. Снижение смертности рассматривалось как важный, необходимый, но не достаточный фактор снижения 
рождаемости. В более поздних своих работах он отходит от такого понимания, обосновывает жесткую причинно-следственную связь между снижением смертности и снижением рождаемости. Указывает, в частности, что снижение смертности началось задолго до промышленной революции, и объясняет, каким именно образом повышение выживания детей повлияло на снижение рождаемости в семьях.

А.Г. Вишневский критикует популярную в 1990-е годы теорию второго демографического перехода за стремление объяснить изменения рождаемости и семейных форм внедемографическими причинами из области семейной экономики, психологии и культурных норм. По его мнению, нет необходимости привлекать к объяснению дополнительные внешние факторы.

А.Г. Вишневский критически переосмысливает современные этапы эпидемиологического перехода, в частности оспаривает получившую распространение концепцию «сердечно-сосудистой революции», рассматривая новейший этап эволюции смертности как продолжение более длительной и фундаментальной тенденции роста ожидаемого возраста смерти в каждом из основных классов причин смерти (Вишневский 2020).

А.Г. Вишневский обосновывает значительную автономность и внутреннюю обусловленность демографических процессов, которые не являются вторичными по отношению к социально-экономическим изменениям. Таким образом, демография предстает в его представлении как независимая переменная. Другие подсистемы общества являются по отношению к ней внешней средой. При этом демографический переход рассматривается не как следствие социально-экономических перемен, a, скорее, как их причина. Демографический переход намного более фундаментален, чем любые социальноэкономические изменения, поскольку он в корне меняет стратегию воспроизводства вида Homo Sapiens.

Автономность демографической системы А.Г. Вишневский связывает с еe способностью к саморегулированию. В ответ на воздействия природной среды или других подсистем общества и его институтов демографическая система адаптируется и таким образом поддерживает равновесие. Даже шоковые воздействия войн, эпидемий и экономических кризисов приводят лишь к временным отклонениям параметров равновесия.

Способность демографической системы сохранять стабильность и отвечать на внешние воздействия обеспечивается механизмом обратной связи. Это обозначается понятием демографического гомеостаза. На современном этапе гомеостаз обеспечивается механизмами целеполагания и свободного выбора на уровне индивидов и семей. Такой механизм регулирования на микроуровне гораздо более гибок, чем старый механизм макроуровневого регулирования. Многообразие индивидуальных решений образует в сумме равнодействующую массового рационального поведения. 


\section{ЗАКЛЮЧЕНИЕ}

Нет ничего более практичного, чем хорошая теория.

Именно теория демографического перехода позволяет понять, почему, например, коэффициент суммарной рождаемости в нашей стране нельзя сегодня поднять до уровня 3 или даже 2,5 детей на женщину. Материнский капитал и другие меры экономического стимулирования рождаемости не приводят к заявленной пронаталистской цели, но все-таки могут быть полезными, поскольку поддерживают семьи с детьми, которые нуждаются в этом.

Та же теория формирует и правильное отношение к долгому повышению смертности, которое растянулось в России на 40 лет с 1965 до 2005 г. Повышенная смертность - тяжелейшее для российского общества бремя. Особенно высокий уровень смертности в 1990-х и в начале 2000-х привел некоторых к мысли о какой-то обреченности нашей страны на потери от преждевременной смертности и отставание от других стран, а некоторых других авторов подтолкнул даже к мысли об «обратном» эпидемиологическом переходе в России. Однако теория демографического перехода толкует стагнацию смертности как очень длительное, но все-таки временное отклонение от ожидаемой общемировой закономерности. В 1970- 2000-е годы снижение смертности в нашей стране тормозилось в силу хорошо изученных сегодня причин. В середине 2000-х Россия встала на путь снижения смертности как только отказалась от советского-постсоветского остаточного принципа финансирования здравоохранения, занялась его модернизацией, приняв также на вооружение хорошо известные и апробированные в других странах меры в области алкогольного регулирования, ограничения курения, просвещения в области здорового образа жизни и правильного отношения к собственному здоровью.

Сегодня наша страна и все человечество стоят перед серьезными вызовами. Быстрый рост населения мира продолжается и приводит к кризисным явлениям. Усиливающаяся миграция из бедных стран глобального Юга в богатые страны Севера порождает социальное напряжение и видоизменяет состав населения принимающих стран. Хотя мировое производство продовольствия в последние полвека росло быстрее, чем население, нельзя гарантировать, что так будет продолжаться и в будущем. Часть регионов сталкивается с нехваткой критических ресурсов и, в первую очередь, дефицитом пресной воды. До сих пор не найдено принципиального решения экологических проблем, например, накопления в природе пластиковых и других вредных отходов. Продолжается глобальное потепление климата и нарастает частота погодных аномалий. Как будет в дальнейшем реагировать на все это демографическая система Вишневского?

К сожалению, сам Анатолий Григорьевич не сможет этого увидеть, проанализировать и отрефлексировать в координатах его системного взгляда на мир и мировое население. Но в целом, зная его конструктивный и оптимистичный характер, можно попробовать предугадать его реакцию. Вероятно, он бы сказал, что демографическая система отреагирует как всегда рационально, а человечество, как и раньше, сумеет найти выход из трудного положения. Он бы сказал просто: «Мы справимся!». 


\section{ЛИТЕРАТУРА}

Вишневский А.Г. (1973). Демографическая революция. Вопросы философии, 2, 53-64.

Вишневский А.Г. (1976). Демографическая револющия. М.: Статистика.

Вишневский А.Г. (1982). Воспроизводство населения и общество. История, современность, взгляд в будущее. М.: Финансы и статистика.

Вишневский А.Г., Волков А.Г. (Ред.) (1983). Воспроизводство населения СССР. Коллективная монография. М.: Финансы и статистика, 1983.

Вишневский А.Г. (1998). Серп и рубль. Консервативная модернизация в СССР. М.: ОГИ.

Вишневский А.Г. (Ред.) (2006). Демографическая модернизация России, 1900-2000. Коллективная монография. М.: Новое издательство.

Вишневский А.Г. (2010). Серп и рубль. Консервативная модернизаџия в СССР. Второе издание. М.: Издательский дом ГУ ВШЭ.

Вишневский А.Г. (2013). Жизнеописание Петра Степановича К. М.: «Знак».

Вишневский А.Г., Тольц М.С. (2015). Незамеченный вклад в теорию демографического перехода. Демографическое обозрение, 2(4), 6-34.

Вишневский А.Г. (2019). Демографическая история и демографическая теория. М.: Издательский дом Высшей школы экономики.

Вишневский А.Г. (2020). Эпидемиологический переход и его интерпретации. Демографическое обозрение, 7(3), 6-50.

Урланис Б.Ц. (1968). История одного поколения (социально-демографический очерк). М.: Мысль.

Chesnais J.-C. (1986). La transition démograhique. Etapes, formes, implications écpnomiques. PUF

Coale A.J., S.C. Watkins (Eds.) (1986). The Decline of Fertility in Europe. Princeton: Princeton University Press.

Coleman D. (2006). Immigration and ethnic change in low-fertility countries: A third demographic transition. Population and Development Review, 32(3), 401-446.

Omran A.R. (1971). The epidemiologic transition: a theory of the epidemiology of population change. The Milbank Memorial Fund Quarterly, 49(4, Pt. 1), 509-538.

Zelensky W. (1971). The hypothesis of the mobility transition. Geographical Review, 61(2), 219-249. 


\title{
ANATOLY VISHNEVSKY \\ AND HIS DEMOGRAPHIC SYSTEM
}

\section{VLADIMIR SHKOLNIKOV}

\begin{abstract}
The article provides an overview of the scientific achievements and creative legacy of the outstanding Russian demographer A.G. Vishnevsky (1934-2021). Vishnevsky's works have become classics, linking within the framework of an integrated demographic theory a huge number of diverse and seemingly disparate facts of demographic history and modernity. The central provisions of Vishnevsky's Demographic System, consistently developed over half a century, took their complete form only by the mid-2010s. The article emphasizes what was new in A.G. Vishnevsky's theory of demographic transition, as well as his decisive role in the institutionalization of Russian demographic science. The article is based on both the works of A.G. Vishnevsky and on the personal experience of many years of creative cooperation with their author.
\end{abstract}

Key words: Vishnesky's demographic system, demographic transition, demographic growth, autonomy of demographic processes.

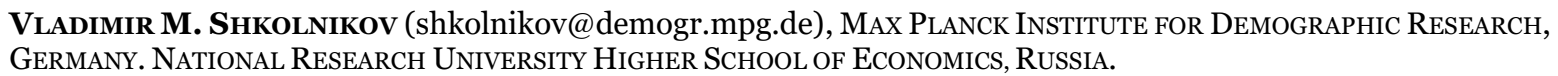

DATE RECEIVED : MARCH 2021.

\section{REFERENCES}

Chesnais J.-C. (1986). La transition démograhique. Etapes, formes, implications écpnomiques. PUF

Coale A.J.,S.C. Watkins (Eds.) (1986). The Decline of Fertility in Europe. Princeton: Princeton University Press.

Coleman D. (2006). Immigration and ethnic change in low-fertility countries: A third demographic transition. Population and Development Review, 32(3), 401-446.

Omran A.R. (1971). The epidemiologic transition: a theory of the epidemiology of population change. The Milbank Memorial Fund Quarterly,49(4, Pt. 1), 509-538.

Vishnevsky A.G. (1973). Demograficheskaya revolyutsiya [Demographic revolution]. Voprosy filosofii, 2, 53-64. (In Russ.).

Vishnevsky A.G. (1976). Demograficheskaya revolyutsiya [Demographic revolution]. Moscow: Statistika. (In Russ.).

Vishnevsky A.G. (1982). Vosproizvodstvo naselenia i obshestvo. Istoria, sovremennost', vzglyad $v$ buduschee [Human reproduction and society. History, modernity and a look into the future]. Moscow: Finansy i Statistika. (In Russ.).

Vishnevsky A.G., Volkov A.G. (Eds.) (1983). Vosproizvodstvo naselenia SSSR [Population reproduction in the USSR]. Moscow: Finansy i Statistika. (In Russ.).

Vishnevsky A.G. (1998). Serp i Rubl. Konservativnaya modernizatcia v SSSR [Sickle and ruble. Conservative modernization in the USSR]. Moscow: OGI. (In Russ.).

Vishnevsky A.G. (Ed.) (2006). Demogtraficheskaya moderizatcia Rossii, 1900-2000.

[Demographic Modernization in Russia, 1900-2000]. Moscow: Novoe izdatelstvo. (In Russ.). 
Vishnevsky A.G. (2010). Serp i Rubl. Konservativnaya modernizatcia v SSSR [Sickle and ruble. Conservative modernization in the USSR]. Moscow: Izdatelskii dom VSHE. (In Russ.).

Vishnevsky A.G. (2013). Zhizneopisanie Petra Stepanovicha K. [Life history of Peter Stepanovich K.]. Moscow: «Znak». (In Russ.).

Vishnevsky A.G., Tolts M.S. (2015). Nezamechennyi vklad v teoriu demograficheskogo perekhoda (An unnoticed contribution to demographic transition theory). Demograficheskoye obozreniye [Demographic Review], 2(4), 6-34. (In Russ.).

Vishnevsky A.G. (2019). Demograficheskaya istoria i demograficheskaya teoria [Demographic history and demographic theory]. Moscow: Izdatelskii dom VSHE. (In Russ.).

Vishnevsky A.G. (2020). Epidemiologicheskii perekhod i ego interpretatcia [Epidemiologic transition and its interpretation]. Demograficheskoye obozreniye [Demographic Review], 7(3), 6-50. (In Russ.).

Urlanis B. Ts. (1968). Istoria odnogo pokolenia (social'no-demograficheskii ocherk) [History of one generation (socio-demographic profile)]. Moscow: Mysl'. (In Russ.).

Zelensky W. (1971). The hypothesis of the mobility transition. Geographical Review, 61(2), 219-249. 